time was increasing in the specificity of the reactions which had been demonstrated by the immunochemical approach, and in the question as to how this specificity arose. Thus antigen handling and antibody production as a function of individual cells, the cell biology of the immune process, became the centre of concentration.

In this book a preparation of antibody is treated essentially as a simple test tube reagent, without concern with its mode of origin. The senior author (and later $\mathrm{Dr}$ Grossberg also) were associated with Linus Pauling and D. H. Campbell in the series of papers in the forties which crowned the efforts of the immuno-chemists and highlighted the need to think next about biosynthetic processes in the cell. $\mathrm{He}$ and his school have kept alive physicochemical thinking at a time when it was comparatively unfashionable in immunology, and this summary of work in the field over the past twenty years is all the more valuable in that now a more sophisticated biology demands once again a precise physico-chemical approach to such problems as modulation of antibodies with time and the still unsolved problem of the origin of specificity.

By and large, then, this is a useful and timely book and a valuable source of information and references. As it represents so much the work of one school, there are naturally points of detail and interpretation which are still controversial, and many items on which one could welcome more discussion. I am disappointed, for example, that there is comparatively little reference to possible conformational changes of the antibody molecule as a whole, both after combination with antigen and after chemical coupling with reagents such as alkylating agents and diazonium salts. Throughout, there is a tendency to treat the antibody combining site in isolation as independent of the rest of the molecule. This approach seems to one like myself, with very little training in the physical chemistry of proteins, to be open to the risk of errors of interpretation. I also have a personal regret that $\mathrm{Dr}$ Pressman, who covers the specificity of antibodies in such expert detail, has nothing to say of the specificity of "delayed" reactions-dependent on a messy biological test though they may be.

The book, however, covers fully the field indicated by its title and is written with great clarity; it has many diagrams of extreme elegance and simplicity, including a number of pictures of molecular models.

P. G. H. GELL

\section{ITCHES AND INFECTIONS}

Red Mites and Typhus

By J. R. Audy. (University of London Heath Clark Lectures 1965, delivered at the London School of Hygiene and Tropical Medicine.) Pp. $x+191$. (Athlone Press, University of London: London, 1968.) $45 s$.

In his Heath Clark Lectures the author adopted for his main theme the ecology of the trombiculid mites and their role in spread of rickettsia infections. This is no mere treatise on the life history of a troublesome parasite, however, but an interesting and at times exciting tale of the annoyance and diseases produced by these red mites at various times and in many places.

The story begins with the observations of the English naturalist Gilbert White on the itch caused by the red harvest mite. It is the larval stages of these mites of the family Trombiculidae, subclass Acarina which attach themselves to the skin of man and animals, but they do not suck blood. Instead they feed on tissue juices and it is their salivary secretion which causes the local irritation known as scrub-itch. In Japan for many years the dreaded Tsutsugamushi disease was known to be associated mainly with the mite Leptotrombidium akamushi, and to occur in localized areas, known as "poisonous places" near certain rivers. When this disease was shown to be caused by a rickettsia ( $R$. orientalis) it was possible to explain the localized areas of infection on ecological grounds. In his wartime studies mainly based on Imphal, the author was able to demonstrate the higher incidence of infection in areas of waste land where the natural balance had been disturbed by cultivation, or wherever cultivated areas had been abandoned. This encouraged the rapid increase in rats, the natural reservoir of the rickettsia and the wild host of the vector mite. Thus troops operating in such areas were liable to suffer outbreaks of scrub-typhus. The text contains many accounts of these outbreaks including the one which took the Royal Navy by surprise when a base was set up in Addu Atoll in 194.1. Another interesting epidemiological facet is the description of the outbreaks of scrub-typhus on the Indo-Burma front. Although this disease was causing concern to the Japanese as well as the Allies, the former failed at first to recognize it as their native Tsutsugamushi disease and even speculated that it might be transmitted by fleas.

Throughout the lecture the author makes interesting comments on many other topics. He discusses research workers, their fantasies and some of their foibles. $\mathrm{He}$ retells the story of the Weil-Felix test, and how a wrongly labelled antigen culture helped to differentiate scrubtyphus from other similar rickettsiae diseases. The ecological accounts are excellent and the author's theory on the evolution of the typhus group of diseases must be read in full to be appreciated. This book can be confidently recommended to the general reader as well as to those specially interested. ANDREW B. SEMPLE

\section{CULTIVATING PARASITES}

The Cultivation of Parasites in vitro

By Angela E. R. Taylor and J. R. Baker. Pp. ix +377. (Blackwell Scientific: Oxford and Edinburgh, 1968.) $70 s$.

THE parasites of animals, to which this work is restricted, comprise a large and heterogeneous collection of species ranging from the simplest of Protozoa to highly complex helminths. The host-parasite relationships, physiological adaptations and life cycles of these organisms cover an equally broad spectrum. Dr Taylor and Dr Baker have performed a phenomenal task in selecting for inclusion in this book the most successful of the innumerable methods that have been proposed for the in vitro cultivation of parasites. Not only do the principles of the media and techniques vary from genus to genus but frequently it is necessary to modify a technique to cater for the foibles of even closely related species, or strains within a single taxon.

The subject has been divided into three parts. The first, dealing with the Protozoa, gives a general account of the problems involved and steps that have been taken to overcome them. Then follow detailed methods for the cultivation of the Trypanosomatidae (trypanosomes and leishmania), the Sporozoa (especially the genus Plasmodium), flagellates other than trypanosomes and ciliates of the intestinal and genital tracts and finally the parasitic amoebae. References are provided conveniently at the end of each of the sections dealing with the major taxonomic groups.

The second part follows the same general plan and covers the cultivation of parasitic helminths in four sections, the Trematoda, Cestoda, Nematoda and Acanthocephala. Throughout these and the previous sections. tables are provided of the most important references to techniques successfully employed for the in vitro cultivation of the various species and, where applicable, the different stages of their life cycles.

A final section deals with general principles of the preparation of apparatus and media as well as giving a very brief account of tissue culture methods. A useful directory 